constraints is rather less rigorous than in Europe or North America was discussed in a special report from the Reuters news agency (2011). In 2008, a total of $78 \%$ of all participants in trials to support drug applications submitted to the US Food and Drug Administration (FDA) were enrolled at foreign sites. In Europe, $61 \%$ of patients in trials submitted to the European Medicines Agency between 2005 and 2009 came from low- and middle-income countries. A further $11 \%$ were from Eastern European countries that had recently joined the European Union.

Here, we present three papers on this contentious subject. The first presents an overview of the challenges from an African perspective. Akwasi Osei is from Ghana, and he debates both the positive and the negative implications of what has become a rapidly developing trend. Second, we learn about the role played by contract research organisations, in a piece by Mariëtte van Huijstee and Nuria Homedes. This is an important article, shedding light on the little-known phenomenon of 'contracting out' clinical trials to organisations over which there is little formal control. Finally, we gain a fascinating insight into the growth of the manufacture and marketing of generic drugs in India, from Anita Kotwani.

\section{References}

Academy of Medical Sciences (2011) A New Pathway for the Regulation and Governance of Health Research. Academy of Medical Sciences.

Reuters (2011) Special report: Big Pharma's global guinea pigs, 6 May. Available at http://www.reuters.com/article/2011/05/06/uspharmaceuticals-trials-idUSTRE7450SV20110506 (accessed March 2012).

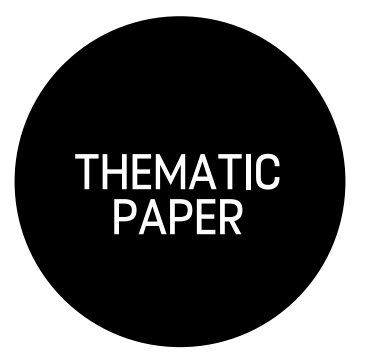

\title{
Challenges of clinical trials in low- and middle-income countries
}

\author{
Akwasi Osei
}

Chief Psychiatrist, Ghana Health Service; Medical Director, Accra Psychiatric Hospital, Accra, Ghana, email akwasiosei@ yahoo.com

\section{Clinical trials have been conducted almost wholly in high-income countries until recently, yet their results may not always be valid or applicable in middle- and low-income countries. Clinical trials are now, though, increasingly being done in less wealthy countries. While this is welcome, there is a need to ensure the profit motive does not override the benefits. Partnership with local counterparts while adhering to international standards should help to maintain high-quality output from clinical trials.}

Clinical trials have been conducted almost wholly in high-income countries until recently, yet their results may not always be valid or applicable in middle- and low-income countries. A welcome recent development is the increasing number of clinical trials being conducted in the latter areas. Growth in the number of trials and their increasing costs in high-income countries are combining with globalisation to shift clinical trials to less wealthy countries (Rowland, 2004). Glickman et al (2009) have shown that about a third of clinical trials conducted by the 20 largest US-based pharmaceutical companies are now conducted outside the USA, many in low-income countries.

Such globalisation of clinical trials obviously confers some benefits to the host countries, including the sharing of experiences and knowledge. It also increases the local availability of the medicines under trial, as well as familiarity with them. The trials bring revenue to the host countries while cutting costs to the pharmaceutical companies by around $10-50 \%$. Clinical trials in India, which is emerging as a favoured global destination for research and outsourced clinical trials, was expected to have earned that country US $\$ 1.5$ billion of revenue by 2010 (Federation of Indian Chambers of Commerce and Industry, 2005).

As welcome as this development is, it brings in its wake challenges, provoking the debate over whether clinical trials in low-income countries are as valid as they are intended to be. Many factors come together to determine the validity of clinical trials, including the number of participants who can be recruited, the affordability and local availability of the medicines, informed consent, and ethical approval from an institutional review body or the agency accredited by the local ministry of health, among others. Ethical approval is a very important consideration, to ensure that nobody is exploited in the course of the trial and that the drug is properly shown to be safe in general application.

In the light of these considerations and challenges, two key questions arise.

- Are clinical trials accurate and reliable in lowincome countries? 
- Do the interpretations given to the results of these trials actually reflect the reality on the ground?

These issues are being raised in this paper to draw attention to the difficulties that may arise in the new global trend for clinical trials to be conducted in low-income countries. Caution is needed in the interpretation of findings from such studies.

\section{Challenges of ethical issues, informed consent and control studies}

It has been suggested that the recent increase in the number of clinical trials being conducted in low- and middle-income countries is not exactly benevolent or altruistic on the part of the pharmaceutical companies. There are various other considerations (Nekkanti, 2008). Profit motives may underlie the clinical trials and this could affect ethical considerations.

It has been shown that as many as $15-25 \%$ of clinical studies conducted in a low-income country do not go through any institutional review board nor any ethics committee, nor have the approval of the ministry of health (Hyder et al, 2004). Even when ethical approval is given, informed consent may be an issue. High levels of illiteracy, cultural barriers, poverty and dependency could negatively influence people's comprehension and ability to give informed consent and can bring into question voluntarism and willingness. The populations of low-income countries, it has been noted (Krosin et al, 2006), are particularly vulnerable in this respect, for various reasons.

Another major issue is the standard of care. The limited resources of poor countries may lead to compromises in standards (Johnatty, 2000), particularly with respect to whether to use placebo in a controlled trial when there is an alternative medicine for comparison. Profit may drive a motivation for placebo to be used when this same standard may not be applied in a high-income country (Tollman et al, 2001). A strong institutional review board could ensure that no country is shortchanged when it is possible to use an alternative drug. The author learned from a colleague at the University of Lagos that, for a clinical trial with the antidepressant paroxetine, in Nigeria in 1995, a drug company insisted on using a small number of patients and an open trial when the local counterpart recommended a case-control double-blind study and a much bigger sample size. The company was considering time and cost and the fact that the drug had been tested elsewhere anyway. The profit motive seemed too strong.

Kent et al (2004) reviewed the published data from randomised clinical trials of HIV treatment, tuberculosis treatment and malaria prophylaxis in sub-Saharan Africa and concluded that there is variable adherence to established clinical guidelines of care, and researchers and ethics committees seem to take the 'local level' of care into consideration.
The case of Pfizer's clinical trials with its new drug in Kano, Nigeria, in the 1996 meningitis epidemic certainly amplifies the issues of ethical considerations and standards of care. Pfizer hastily took advantage of the epidemic to test its new drug, hoping to make a multimillion dollar profit. Several lawsuits against Pfizer resulted and there has been a large out-of-court settlement (World Press Review, 2001; Stephens, 2009).

Another major concern is that at the end of a trial the drug may not be affordable because the purchasing power of clients in low-income countries may be too low, especially where there is no health insurance system that can cushion them. Thus, a person who participates in a trial testing a new medication may not ultimately be able to benefit from the drug.

\section{Conclusion}

While the globalisation of clinical trials is a welcome phenomenon for the positive benefits it brings to both the host country and the pharmaceutical companies, there is a need to watch critically that the profit motive does not override the benefits. Care should be taken to interpret the resulting data, taking into consideration the challenges of informed consent. Partnership with local counterparts while adhering to international standards should help to maintain high-quality output.

\section{References}

Federation of Indian Chambers of Commerce and Industry (2005) White Paper on Global Clinical Trials in India: Prospects and Challenges. FICCI.

Glickman, S. W., McHutchison, J. G., Peterson, E. D., et al (2009) Ethical and scientific implications of the globalization of clinical research. New England Journal of Medicine, 360, 816-823.

Hyder, A. A., Wali, S. A., Khan, A. N., et al (2004) Ethical review of health research: a perspective from developing country researchers. Journal of Medical Ethics, 30, 68-72.

Johnatty, R. N. (2000) Clinical trials in developing countries: discussions at the 9th International Symposium on Long Term Clinical Trials. Current Controlled Trials in Cardiovascular Medicine, 1, 55-58.

Kent, D. M., Mwamburi Mkaya, D., Bennish, M. L., et al (2004) Clinical trials in sub-Saharan Africa and established standards of care: a systematic review of HIV, tuberculosis and malaria trials. JAMA, 292, 237-242.

Krosin, M. T., Klitzman, R., Levin, B., et al (2006) Problems in comprehension of informed consent in rural and peri-urban Mali, West Africa. Clinical Trials, 3, 306-313.

Nekkanti, M. (2008) Clinical Trials in Developing Countries: Ethical Considerations. Knol. Available at http://knol.google.com/k/manalinekkanti/clinical-trials-in-developing-countries/1h1 wfnf2oeoie/2 (accessed March 2012)

Rowland, C. (2004) Clinical trials seen shifting overseas International Journal of Health Services, 34, 555-556.

Stephens, J. (2009) Pfizer to pay $\$ 75$ million to settle Nigerian Trovan drug-testing suit. Washington Post, 31 July. Available at http://www.washingtonpost.com/wp-dyn/content/ article/2009/07/30/AR2009073001847.html (accessed April 2012).

Tollman, S. M., Bastian, H., Doll, R., et al (2001) What are the effects of the fifth revision of the Declaration of Helsinki? BMJ (Clinical Research Edition), 323, 1417-1423.

World Press Review (2001) April issue (vol. 48, no. 4). 